\title{
Synergy of interaction of control and supervisory structures in ensuring the stability of the socio-economic system: principles and organization
}

\author{
Vyacheslav Bezdenezhnykh ${ }^{1}$, Anastasiya Bezdenezhnykh², and Elena Karanina ${ }^{3, *}$ \\ ${ }^{1}$ Financial University under the Government of the Russian Federation, Leningradsky Prospekt, 49, \\ 125993 Moscow, Russia \\ ${ }^{2}$ KPMG International Limited (“KPMG International”), Olimpiyskiy Prospekt, 16, building 5, \\ 129110, Moscow, Russia \\ ${ }^{3}$ Vyatka State University, Moskovskaya St., 36, 610000 Kirov, Russia
}

\begin{abstract}
The article examines the system of interaction of control and supervisory services and structures (CSS) in the process of managing the development of socio-economic systems (SES). The system of interaction of the CSS is considered as a complex independent dynamic regulated process. The new concept of "synergy management system (SMS) of interaction" of control and supervisory services of complex socioeconomic systems is substantiated. The basic principles and structure of the organization of the system of management of synergy of interaction of CSS are proved. It is noted that in the theory of complex synergetic systems, an important place belongs to the processes of self-regulation in local areas. It is shown that the existence of mechanisms for implementing self-regulation indicates the maturity of synergy management systems. The essential functions and principles of the organization of the system of interaction between control and supervisory services are highlighted, and the concept of complexity and maturity of this system is revealed. Methods of reducing the risks of possible implementation of negative events when coordinating within a self-regulating system for managing the synergy of interaction of subsystems are indicated. It was also emphasized that a mandatory aspect aimed at establishing the work of the SMS is a methodically based assessment of the effectiveness of the management systems for the synergy of interaction between control and supervisory services.
\end{abstract}

\section{Introduction}

The interaction of control and supervisory services and structures (CSS) in the process of managing the development of the socio-economic system (SES), which can include enterprises and organizations from the micro to macro level, is considered as a complex independent system process. The number of such services, depending on the regulated SES

\footnotetext{
*Corresponding author: kafinanc@yandex.ru
} 
itself, can vary from $12-15$ to 50 or more $[1,2]$. Their administrative subordination may also be inconsistent, which creates a conflict of interests between these services when solving the problem of improving the efficiency of their interaction. The process of interaction of the CSS has its own organization, a certain set of constituent elements connected by various relationships, a resource, legal and methodological basis as the basis for formation. Setting goals for coordinating the work of control and supervisory services, in most cases, is aimed at improving the effectiveness of interaction between control bodies in the management of SES in order to ensure the sustainable and safe implementation of the tasks of this organization. Interaction of divisions as a regulatory process can be implemented in the following modes: controlled by an external regulator of the General management of the socio-economic system; self-regulating interaction process; or in a mixed mode, using elements of both self-regulation and external management of the interaction process. The choice of regulation of process of interaction of the SMS is determined by the level of complexity of the SES, the corresponding complexity of the overall management of SES and level of complexity of the control and supervision of the services. It should be noted that currently complex socio-economic systems operate in an unstable environment characterized by turbulence, crises of various nature, heterogeneity of the economic space and the pace of economic development. In this paper, the process of interaction of the CMC is considered as a dynamic complex system characterized by the availability of internal resources, openness to external influences, on the one hand, adaptability and flexibility of internal inter-structural interaction, on the other. The scientific hypothesis investigated in this paper is to consider the process of interaction of the SES as a complex open dynamic, nonlinear system that uses internal and external resources and can, due to the synergy of this interaction, increase the effectiveness of the overall management of the SES while ensuring stability, safety and implementation of the goals of operation.

\section{Materials and methods}

The organization of the synergy management system (SMS) of the interaction of the CSS in the management of a complex socio-economic system requires more detailed consideration. Based on the analysis of corporate governance practices, the system CSS has the following set of characteristics that describe its operation:

- element composition, including policies, standards, methods and other resources (personnel, information, technical means, etc.);

- levels of organization and solutions, dispatching and administration;

- estimated indicators of the degree of maturity of functioning, provided in the necessary and sufficient volume.

Let's describe each of the elements of the synergy management system in more detail. The main components include the following:

- organizational structure (levels characterized by indicators of maturity, flexibility, openness, complexity, etc.): interacting subsystems with their own functionality, relationships and connections of subsystems, subordination (information, administration, reports, financing, etc.);

- processes in the synergy management system (in space and time);

- methodological resource: strategies, policies, methods and techniques for conducting work, investigations, reports, analysis, etc.;

- IT- support, including databases and methods of processing and analysis;

- human resources, including knowledge, skills, information, competencies, qualifications; experience, as well as soft-skills.

Let's consider the characteristics of the SMS system, such indicators as the level of maturity of the interaction organization system, the content and functional composition, and 
possible levels of the SMS organization. In order to reveal the essence of the studied levels of SMS, we outline important, in our opinion, principles and qualitative characteristics of management processes, such as, for example:

(1) the principle of localization of powers and responsibilities,

(2) the principle of integration in the process and in making decisions

(3) the principle of improving the quality (as opposed to simplification) of decisions

(4) the principle of utility (assistance in making decisions) for the entire system of risk management and general management SES

(5) the principle of the weighted (based practice real, not formal) risk evaluation.

An important condition that has been studied in a number of papers $[3,7]$ is that the level of complexity of solutions correlates with the level of complexity of the management tasks to be solved for coordinating the interaction of the CSS. Some tasks have the standard nature of a management decision, do not require a higher level of regulation, and are not investigated in this study.

Next, we will consider the concept of the level of maturity of the SMS functions. It should be emphasized that the level of maturity of the synergy management system (CMS) and the risk management system (ERM) differ in content. The methodology for assessing the maturity levels of risk management is quite well developed in a number of standards, for example, the COSO ERM risk management standards (USA), in which the methods for assessing maturity are updated almost annually. For the methodology of assessing the maturity of the SMS, it is not yet methodically accurate and fully justified by the control indicators. This is, firstly, a verbal (qualitative) and, secondly, a measurable (quantitative) characteristic and evaluation procedure, i.e. a method for determining how to measure this maturity of system functions. The level of maturity of the synergy management system functions is often determined by indicators of management complexity. It is proposed to apply this approach to assessing the maturity of the SMS. Moving on to a concept more researched than maturity-the concept of complexity, we can characterize the level of maturity of the SMS. Note that there are different definitions of complexity. Based on the goal - to achieve a synergistic effect of the interaction of SMS, it would be useful to consider the concept of complexity of the processes of synergistic systems $[10,11,17]$. For now, at the first stage of the analysis, we will leave the content of synergy out of the discussion. For the purpose of selecting a measure of the indicator, let's discuss a comparative characteristic of complexity, which is somewhat easier to measure the absolute indicator. Compare the three levels: complexity of SES, complexity total management and complexity of SMS and assume that the normal maturity level is the level of complexity of the SMS, which should correspond to the complexity of the management of the organization and the level of complexity of the organization itself. Here we list some qualitative characteristics of the complexity (and, accordingly, maturity) of the SMS.

1. In the theory of complex synergetic systems, an important place belongs to the processes of self-regulation in local areas where the level of regulation is lower than in the entire system $[7,12,13]$. The existence of mechanisms for implementing self-regulation indicates the maturity of the SMS.

2. the next characteristic of the maturity of ERM processes is the presence of two modes: (1) systematically and regularly; (2) selectively and pointwise for projects or new manifestations. This important indicator of consistency is that both risk management mechanisms start working at the right time and in the right place.

3. another characteristic of the maturity of the SMS is the level of sufficiency of methodological study of management problems. A study of the approaches proposed by researchers in the field of risk suggests that such approaches are very different. In the initial model of the hypothesis adopted in this paper, we consider the process of interaction of $\mathrm{CSS}$ as a complex, open, dynamic, nonlinear system that uses internal and external 
resources and is able to use the synergy of this interaction. Methodological support should also support the quality of adaptability and self-adjustment of the SMS [15,16].

In our opinion, these are the main, but not exhaustive, features and characteristics of the system that allow us to talk about the maturity and readiness of the system to manage synergy in the system of interaction of the CSS.

We will focus further on the issues of integration of interaction of subsystems in a complex multi-level and developing system-SES. Why are there negative (conflict) or positive (sometimes the first turn into the second) effects of their interaction? We list these subsystems, it may not be exhaustive, but approximate composition. There are mandatory structures and coordination systems that define the components and content of the SMS processes in the socio-economic system, created in accordance with state and departmental regulatory documents, as well as their internal corporate regulations related to the history of SES formation, management traditions, staff experience, top management position and the composition of the decision making person (DMP).

The most common is the internal audit system (IAS). Audit committees first appeared in the USA, and then in other countries, after the Sarbanes-Oxley Act (2002) [14]. Paragraph 1 of the "Law ..." States: each issuer must form an Audit committee. The audit committee is a collegial body that usually includes representatives of the decision-making structure that provides general management (the Supervisory Board or the Board of Directors), created to solve the following tasks (tasks may be specified in each case):

* audit of financial accounting indicators;

* audit of accounting policies;

* audit of internal control procedures for financial indicators;

* monitoring of external audit processes and coordination of interaction between external and internal audit;

* coordination of three levels of protection (audit) at the operational, operational and strategic control levels.

Later, in the standard KOSO-2 (USA), the internal control (audit) system was supplemented with a risk management system, which also became a mandatory element of the system of control and supervision and countering fraud and other illegal actions [18]. The extension of this provision on the Audit committee to Russian enterprises is quite active, especially for companies working with foreign companies in international markets. But in domestic conditions, its implementation has some specific features [4,8]. Thus, under Russian law, the formation of independent audit committees is not mandatory. At the same time, a number of legislative acts were adopted to implement a risk management system (or certain types of risk management, such as state property management, legalization of illegal income, corruption risks, etc.), which are mandatory for economic entities of the country. Problems also include possible informal relationships (affiliations) between the company's management and participants, or the incompetence of members of such audit and risk management committees.

The main provisions determining the required connection of an external control factor and balancing the energy of the external environment as a resource synergy, mature internal control and supervisory system (e.g., auditing) structures, include the following:

- special certified analytical (e.g., accounting) training and relevant professional knowledge and skills of analysts. The structure must include at least three people who do not have any affiliated relations with the company;

- the activity of the structure should be determined by the relevant regulatory and methodological document adopted by the top management of the organization;

- the committee's function includes mandatory annual public analysis of the report on external control (for example, auditing) by the regulator; 
-the function of control and supervision services (including internal top management committees) is to analyze all production and financial and economic reports of an economic entity jointly with employees of an external audit company and senior managers;

* holding regular and special meetings with analysts and senior managers of the enterprise on the assessment of its benchmarks and dynamic (gradient) characteristics;

* joint analysis of the main policy (strategic) guidelines related to the risk management system and ensuring the sustainability of the SES operation with specialists-analysts and senior managers of the enterprise;

* joint analysis of control and supervision processes with employees of an external supervisory audit company, primarily those aspects of activity that are insignificant for the company's top management;

* control of personnel policy in relation to the composition of the control and analytical group.

Further, without considering the substantive aspects of these structures, let's name some other coordinated subsystems of sustainability, the economic security of the SES coming on a synergistic assessment of possible risk events and strategic decisions in the business entity, namely:

Internal control system (ICS)

The system of compliance-control (k-control),

Risk management system (ERM),

system of monitoring processes and assessment of management effectiveness,

The system of counteraction to corruption, fraud and other illegal acts,

Quality management system,

The system of information security,

The system of economic security,

Environmental safety management system,

The office of adviser to decision-makers in audit, environment, risk analysis and economic security,

Office of the Supervisory Board for financial reporting,

The system of labour protection,

Control system for technological and other requirements,

Personnel management system and others that take into account the peculiarities of different fields of activity.

Thus, even a simple (i.e. not organized in a synergistic sense) coordinated management of the interaction of 12-15 subsystems in order to achieve strategic goals (increase synergy with minimal energy consumption) is not an easy task, and managing the synergy of interaction, especially requires the availability of management tools, mechanisms and resources. This is another condition for success in SMS.

\section{Results}

Summing up the results of the first stage of the analysis, we note that methods for reducing the risks of possible implementation of negative events were indicated when coordinating within a self-regulating system for managing the synergy of interaction between subsystems. The essential qualities and principles of the SMS interaction of the CSS are noted, as well as the concept of complexity and maturity of this system is revealed. But the presence of a synergy management system does not exhaust all these conditions. These are necessary, but not yet sufficient factors. In our opinion, one of the key aspects of effective implementation of the SES by interaction processes is the position of the top management of the SES. In the risk management standards, this aspect is called "tone from above", i.e. 
an active, open, systematic position of support for the CSS processes by strategic decisionmaking structures.

Note that this aspect is also one of the indicators of the maturity of ERM. To put together a mature system with complex interaction processes, as practice shows, it will take at least 2-3 years, and even more with modifications and corrections. International practice sets a period of not less than 7-8 years. First of all, we need a project team that is experienced, knowledgeable, and qualified, but relies on the trust of the motivator driver in the person of the DMP and the constant help of his advisers on this topic.

In some regulations risk management systems (ERM) are formed according to the requirements of the Regulator (in Russia the Bank of Russia, Rosfinmonitoring, Moskomimushestvo, Ministry of Laboure and social protection, etc.). Unfortunately, as shown by the results of the monitoring in government agencies, the systems operate with low efficiency even in some of its elements [8], not to mention the formation of synergetic interaction effect of the CSS. There is no effectively built-up mature SMS processes of interaction between control and supervisory services and structures, this is the most important condition for the quality of work. So far, not everything is working out at different levels of the state risk management system (for example, the low level of implementation of state development programs and national projects in 2012 -2019), including the system for managing the synergy of interaction between control and Supervisory structures. In our opinion, the requirement of successful implementation of ERM in every complex socio-economic system is an urgent requirement for ensuring the stability and security of a complex socio-economic system.

The second key point aimed at establishing the work of the SMS is the correct assessment of the effectiveness of the SMS. In a number of risk management standards, performance assessment is a mandatory section [18,19] (note that the number of standards is growing, in Russia there are more than 20 risk management standards in various fields of activity). This assessment is of interest to the DMP structures, the regulator, the analysts themselves, as well as all performers, all participants in the management process. The assessment can be reduced not only to cost indicators. For example, indicators of the quality of risk analysis, the effectiveness of specific risk management, the accuracy of decision-making at different levels, in subsystems, in the SMS and in management in general also allow you to assess the effectiveness of ensuring the stability and safety of SES. But the most obvious is the comparison of the quality "before "and" after " the introduction and development of a new management synergy management system.

Performance assessment can relate to individual management processes, individual projects in an organization, the feasibility of a business plan, estimates of the achievability of goals, the intensity of tasks, and the amount of residual risk (within the risk appetite). The effectiveness study requires additional special analysis and discussion, because there are unresolved methodological issues of evaluation, as well as measurement difficulties due to the dynamics of changes in the context of SES functioning.

Another key condition is that the knowledge, skills, methods and qualification of performers. Note that the modern assessment and calculation apparatus for risk analysis is quite complex, you need specialized knowledge of mathematics, economics, sociology, accounting, law, management theory, organization management, specialized software products, professional standards, and a foreign language (preferably two). After conversations with practitioners of risk analysis questions about the qualifications of such specialists, this list of disciplines has always expanded. But having a professional standard of a risk management specialist and a compliance control specialist can help solve this problem to some extent. An important contribution is made by corporate training (new specialists, new methods, updating existing programs). 
It is also necessary to develop certification and evaluation of training in the Russian (and not only in Russia) professional community, to introduce public (not state) licensing and certification, registration and maintenance of registers of experts to ensure that quality of work is provided by qualified performers. Public associations such as the American Association of risk and insurance (ARIA), the international Association of professional risk managers (PRMIA), and the Society for risk and insurance management (RIMS) also prove this. In Russia, this is the «RusRisk» Association, the Association of economic security experts, and others. While these issues are being resolved, in our opinion [8], as well as in the opinion of international experts, it is not adequate to the market requirements and socioeconomic processes.

The risks of managing the SMS processes of interaction of the CSS of an economic entity, taking into account the analysis of behavioral risks, have their own characteristics. In fact, the problem of personnel is a multi-faceted one.

We should also emphasize the importance of using financial and economic resources as a component of ensuring effective management. The activity of any organization is determined, among other things, by a balanced ratio of available assets, non-current assets, working capital and labor resources. Despite the apparent triviality of this remark, there are many methodological issues in assessing the balance structure as a condition for sustainable development. A number of recent dissertation studies are devoted to proving this position. In other words, the structure of the balance sheet, including such an asset as human capital, is one of the main factors determining the successful development of SES. On the one hand, people manage risks, and on the other hand, people form and implement risk events for the organization, determining the synergistic potential. Risk is contained both in the process of forming a human resource and in the process of changing it. There is also a humanitarian and mental problem directly related to governance. Practice shows that an organization with more than ten employees needs a management system at different levels. Ensuring the sustainable functioning of such a system becomes a difficult management problem. This is caused by the behavior of managers and performers of the system, which reflect the irrationality of many decisions. D. Kahneman and A. Tversky made a great contribution to the theory and methodology of analysis of irrational behavior [9]. Behavioral risks based on the results of the practice of consulting investigative organizations in identifying, including fraudulent actions and schemes, can be grouped as follows:

-irrationality of top management (criminal actions of top managers, kickbacks, theft).

- irrationality of middle-level management - stealing trade secrets, taking business to their own structures.

- irrationality of competitors - causing intentional or unintentional harm to the company.

- staff irrationality - incompetence, making unreasonable, incorrect decisions, short-term decisions without taking into account long-term consequences.

- irrationality of the primary level of management - disloyalty, criminal actions of ordinary staff (criminal actions of staff. random errors, incompetence).

- disorganization, protest activity, unreasonable collective demands and pressure.

- lack of motivation, interest in the result, low work intensity, falling productivity, downtime.

Behavioral risk management mechanisms complement existing ones in a number of ways and include the following:

- attracting qualified and already proven in practice and well-known professionals in the market;

- promotion (selection, training, certification, motivation) to the level of top managers of loyal and successful middle managers.

- a well-thought-out transparent system for motivating top managers, which creates an interest in long-term stable business development. 
- business planning, monitoring, control of key performance indicators, taking into account the peculiarities of behavioral irrationality of the staff. Thus, a generalized register of issues of practical risk management of economic entities was defined, taking into account the SMS.

\section{Conclusions}

The analysis made it possible to establish and justify the following provisions. The scientific hypothesis investigated in this paper, namely, the consideration of the process of interaction of the SES as a complex open dynamic, nonlinear system that uses internal and external resources and is able to increase the effectiveness of the overall CES management due to the synergy of this interaction, has good scientific, methodological and practical prospects.

The characteristics of each of the main elements of the synergy management system of interaction between control and supervisory departments and services in order to ensure the stability and safety of complex socio-economic systems are highlighted and given. The characteristics of the TOM system and the selected indicator of the level of maturity, the organization of interaction as a key to assess the effectiveness of the WMS.

The principles and qualitative characteristics of management processes are justified to reveal the essence of the studied levels of the SMS. In the initial model of the hypothesis adopted in this paper, we consider the process of interaction of CSS as a complex, open, dynamic, nonlinear system that uses internal and external resources and is able to use the synergy of this interaction.

The paper outlines methods for reducing the risks of possible implementation of negative events when coordinating within a self-regulating system for managing the synergy of interaction of subsystems. The article substantiates the essential qualities and principles of the SMS interaction of the CSS, as well as reveals the concept of complexity and maturity of this system. It is concluded that the presence of a synergy management system does not exhaust all these conditions.

The maturity of the interaction management system is ensured by the use of methods for evaluating effectiveness, which can be studied at different stages and individual management processes, to individual projects in the organization, to the feasibility of the business plan, to assess the achievability of goals, the intensity of tasks, the size of the residual risk (within the risk appetite). The paper identifies unresolved methodological issues of assessment, as well as measurement difficulties due to the dynamics of changes in the context of CES functioning, which require additional analysis and discussion. The role of employees ' skills in identifying, processing and managing risks in assessing the maturity of the SMS is emphasized. Having a professional standard of a risk management specialist and a compliance control specialist can help solve this problem to some extent. Targeted inhouse training and professional development on these issues make an important contribution. It is also necessary to develop qualification issues in the Russian professional community, introduce public (not state) certification and competency test, record and maintain registers of specialists, so that the quality of work is ensured by the qualification of performers.

\section{References}

1. V.I. Avdiysky, V.M. Bezdenezhnykh, Uncertainty, variability and inconsistency in problems of risk analysis of the behavior of economic systems, Effective anti-crisis management 3, 66, 46-61 (2011) 
2. V.I. Avdiyskiy, V.M. Bezdenezhnykh, The development of risk-management techniques in order to improve the quality control-supervisory activities, Espacios 39, 39 (2018)

3. V.I. Avdiyskiy, V.M. Bezdenezhnykh, N.G. Sinyavsky, Modern scientific approaches to the development of risk minimization systems in the activities of economic entities (Monograph. M.: 2019)

4. V.I. Avdiyskiy, V.M. Bezdenezhnykh, Economic security of modern Russia: a riskoriented approach to its provision, Economy. Taxes. Right 9, 3, 6-13 (2016)

5. V.I. Avdiyskiy, V.M. Bezdenezhnykh, Economic security and stability of complex socio-economic systems. In the collection: Problems of development of modern socioeconomic systems (POWER-2014). Materials of the International scientific and practical conference. Siberian state University of railway transport 9-24 (2015)

6. V.M. Bezdenezhnykh, Standard for ensuring economic security of an economic entity, Economics and management 4, 79 (2014)

7. V.M. Bezdenezhnykh, M.N. Lepeshkina, Problems of uncertainty and risk management in the functioning of complex systems-the limit uncertainty theorem. In: Managing the development of large-scale systems (mlsd '2011). Proceedings of the fifth international conference (2011)

8. V.M. Bezdenezhnykh, Expert assessment of the implementation of the national plan for combating corruption and anti-corruption plans of Federal Executive authorities of the Russian Federation, Economics and management: problems, solutions 3, 8, 39-47 (2017)

9. D. Kahneman, P. Slovik, A. Tversky, Decision-making in uncertainty: rules and prejudices (Kharkiv: Publishing house Institute of applied psychology "Humanitarian Center", 2005)

10. E.N. Knyazeva, S.P. Kurdyumov, Bases of synergetics. Modes with peaking, selforganization, temporary (St. Petersburg: aleteya, 2002)

11. G.G. Malinetsky, A.B. Potapov, Modern problems of nonlinear dynamics (Ed. 2nd, corrected and additional-M.: editorial URSS, 2002)

12. G. Nikolis, I. Prigozhin, Self-organization in non-equilibrium systems (Moscow: Mir, 1979)

13. S.P. Obukhov, Self-organized criticality: Goldstone modes and their interactions, Phys. Rev. Lett. 65, 12, 1395-1398 (1990)

14. Sarbanes-Oxley Law (Pub. L. 107-204, 116 Stat. 745, entered into force on July 30, 2002) https://ru.qaz.wiki/wiki/Sarbanes\%E2\%80\%930xley_Act (accessed 15.11.2020)

15. P. Bak, C. Tang, K. Wiesenfeld, Self-organized criticism, Phys. Rev. A. 38, 1, 364-374 (1988)

16. P. Bak, K. Chen, Self-organized criticality, In the world of science 3, 16-24 (1991)

17. P. Bak, How nature works: The science of self-organized criticality. Springer-Verlag, New York, Inc. (1996)

18. The Committee of Sponsoring Organizations of the Treadway Commission. (COSO) "Conceptual framework for internal control". New Guidance: Compliance Risk Management - Applying the COSO ERM. (version from 11.11.2020). https://www.coso.org/documents/coso_ERM_ExecutiveSummary_Russian.pdf (accessed 15.11.2020). 
19. Standard of Russia ISO 31000-2019 risk Management. Principles and guidelines. Date of introduction 2020-03-01. http://docs2.kodeks.ru/document/1200170125 (accessed 15.11.2020). 